
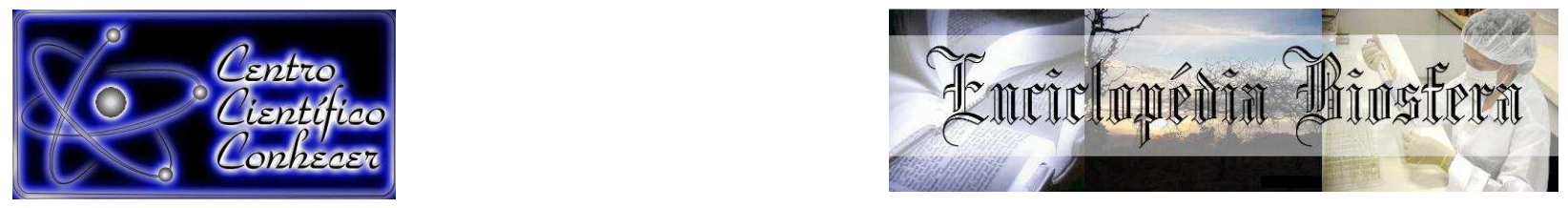

\title{
BIOMETRIA DE FRUTOS E SEMENTES E GERMINAÇÃO DE Sorocea muriculata MIQ. (MORACEAE) NATIVA DO ACRE, BRASIL
}

Ednéia Araújo dos Santos ${ }^{1}$, Romário de Mesquita Pinheiro², Evandro José Linhares Ferreira $^{3}$, Marilene de Campos Almeida ${ }^{4}$

1 Engenheira Florestal, Mestre em Botânica, Instituto Nacional de Pesquisas da Amazônia - INPA, Rio Branco, Acre (edneiasantos_14@hotmail.com)

2 Graduando em Engenharia Agronômica, Universidade Federal do Acre, Instituto Nacional de Pesquisas da Amazônia - INPA, Rio Branco, Acre

3 Engenheiro Agrônomo, Doutor em Botânica, Pesquisador do Instituto Nacional de Pesquisas da Amazônia - INPA, Rio Branco, Acre

4 Engenheira Agrônoma, Doutora em Biologia Vegetal, Laboratório de Sementes Florestais do Parque Zoobotânico da UFAC, Rio Branco, Acre

Recebido em: 08/09/2015 - Aprovado em: 14/11/2015 - Publicado em: 01/12/2015 DOI: http://dx.doi.org/10.18677/Enciclopedia_Biosfera_2015_103

Sorocea muriculata (Moraceae) é uma espécie arbóreo-arbustiva distribuída na Amazônia e na Mata Atlântica explorada com fins medicinais. Este estudo descreve as características biométricas de racemos, frutos e sementes e a germinação das sementes da espécie. $\mathrm{Na}$ avaliação biométrica, realizada no Laboratório de Sementes Florestais do Parque Zoobotânico da Universidade Federal do Acre, em Rio Branco-Acre, foram utilizadas amostras de 30 racemos, 100 frutos e 100 sementes. Para o teste de germinação foram utilizadas 100 sementes. Os dados da biometria foram analisados no programa BioEstat 5.0 ® e os cálculos do percentual de germinação, tempo e velocidade de germinação no programa Microsoft Office Excel 2010. Os racemos maiores apresentaram maior número de frutos e maior massa. Os frutos mais pesados apresentaram sementes maiores, maior profundidade de polpa e, em geral, maior percentual de polpa em relação ao de semente. Apenas $42 \%$ das sementes germinaram. A germinação teve início no vigésimo oitavo dia e se estendeu por mais 45 dias. Concluiu-se que os frutos de $S$. muriculata com maior massa total tiveram maior massa de polpa e de semente. As sementes apresentaram germinação baixa e irregular.

PALAVRAS-CHAVE: Amazônia, Espécie nativa, Floresta Estadual do Antimary

\section{FRUITS AND SEEDS BIOMETRY AND GERMINATION OF Sorocea muriculata MIQ. (MORACEAE) NATIVE OF ACRE, BRAZIL}

\begin{abstract}
Sorocea muriculata (Moraceae) is a tree and shrub species distributed in the Amazon and Atlantic Forest exploited for medicinal purposes. This study describes the biometric characteristics of racemes, fruits and seeds, and germination of $S$. muriculata seeds. The biometric evaluations, performed at the Forest Seeds
\end{abstract}


Laboratory of the Zoobotanical Park of the Federal University of Acre, in Rio Branco, Acre, used 30 racemes, 100 fruit and 100 seeds. The germination test used 100 seeds. The data were analyzed in the statistical program BioEstat $5.0 \AA$ and the calculations of the percentage of germination, time and speed of germination in Microsoft Office Excel 2010. The larger racemes presented more fruit and were heavier. The heavier fruits had bigger seed, greater depth of pulp and, in general, higher percentage of pulp relative to the seed. Only $42 \%$ of the seeds germinated. Germination began at the twenty-eighth day, lasting another 45 days. It was concluded that heavier fruits of $S$. muriculata had larger mass of pulp and seed. The seeds showed irregular and low percentage of germination.

KEYWORDS: Native species, Amazon, Floresta Estadual do Antimary

\section{INTRODUÇÃO}

O gênero Sorocea pertence à família Moraceae e é composto por aproximadamente 25 espécies que se distribuem principalmente na região oeste da Amazônia e na Mata Atlântica. A principal característica morfológica do gênero são as suas folhas com margem frequentemente espinescente. Várias espécies, com destaque para S. guilleminiana Gaudich. e S. bonplandii (Baill.) W.C. Burger, Lanj. \& de Boer, são tradicionalmente utilizadas na medicina popular para tratar de inflamações e úlceras gástricas, além de reconhecida por sua ação analgésica e anticoagulante (PEREIRA, 2005; ROSS et al., 2008; LEONHARDT et al., 2011; SOUZA \& LORENZI, 2012).

Sorocea muriculata Miq., conhecida popularmente como cafezinho, é uma espécie com hábito arbóreo-arbustivo cuja altura pode variar entre 2 e $13 \mathrm{~m}$ de altura que cresce no sub-bosque de florestas de terra firme nas Guianas, Suriname, Venezuela, Colômbia, Equador, Peru, Bolívia e no Brasil, no Centro-Oeste e na região norte, especialmente no Acre e no Mato Grosso (BERG \& AKKERMANS, 1985; HERBÁRIO INPA, 2015). Também cresce em florestas secundárias e por essa razão tem potencial de ser utilizada para a recuperação de áreas degradadas. Seu tronco possui base reta, com ritidoma castanho a acinzentado com lenticelas circulares, casca morta papirácea, casca viva creme, estriada, não fibrosa e látex branco a marrom, abundante ou escasso. Possui inflorescência do tipo racemo, com raque de coloração avermelhada, leve odor adocicado e botões florais verdeamarelados. Os frutos carnosos são do tipo baga, indeiscentes e apresentam coloração avermelhada quando imaturos e arroxeada a preta quando maduros. Suas sementes são esverdeadas e elipsoides (HERBÁRIO INPA, 2015).

Embora muitas espécies arbóreas nativas possuam potencial para uso na restauração de áreas degradadas, arborização urbana, medicinal, exploração de produtos madeireiros e não madeireiros, e melhoramento vegetal, esse potencial tem sido limitado pela carência de informações e estudos sobre essas espécies. No caso de Sorocea existem vários estudos sobre a composição química e a utilização medicinal de algumas de suas espécies, no entanto, estudos biométricos de frutos e sementes, germinação, armazenamento e ecologia ainda são escassos.

A importância dos estudos biométricos é grande. Suas informações podem ser usadas para subsidiar outros estudos e projetos voltados para a conservação e a exploração racional dos recursos naturais com valor econômico, ajudar no direcionamento de trabalhos de melhoramento de espécies vegetais, além de fornecer informações que auxiliam na distinção entre espécies do mesmo gênero (GUSMÃO et al., 2006; BATTILANI et al., 2011; CHRISTRO et al., 2012; 
GONÇALVES et al., 2013). Outra informação relevante para viabilizar a utilização de espécies florestais é a que diz respeito às formas de propagação e ao armazenamento das sementes (ALVES et al., 2012; FELIPPI et al., 2012a; FELIPPI et al., 2012b; FERREIRA, et al., 2012; HERZOG et al., 2012; DORNELES et al., 2013; DRESCH et al., 2013; KRATZ et al., 2013). Entretanto, ainda são poucos os estudos que abordam o tempo que as espécies levam para germinar, qual sua porcentagem de germinação, se suas sementes apresentam dormência e qual o melhor modo de armazenamento das mesmas.

Assim, o objetivo deste trabalho foi caracterizar biometricamente os racemos, frutos e sementes, estabelecer possíveis correlações entre as variáveis relacionadas à massa e dimensões dos frutos e sementes e avaliar a capacidade germinativa de sementes de Sorocea muriculata através da porcentagem, da velocidade e do tempo médio de emergência.

\section{MATERIAL E MÉTODOS}

Os racemos e frutos utilizados nesse estudo foram colhidos de plantas existentes na Floresta Estadual do Antimary (FEA), localizada no município de Bujari, Acre, entre os paralelos de 09 $13^{\prime}$ e 09 $31^{\prime}$ de latitude sul e os meridianos de $68^{\circ} 01^{\prime}$ e $68^{\circ}$ 23' de longitude oeste, em 22 de dezembro de 2012. A vegetação presente na FEA é do tipo floresta tropical úmida e os tipos vegetacionais predominantes são floresta aberta com bambu, floresta semi-densa com bambu, floresta densa com bambu e floresta densa uniforme. A região possui clima quente e úmido com dois períodos climáticos bem definidos: uma estação chuvosa que vai do mês de novembro a abril e uma estação seca que vai do mês de maio a outubro (SILVA, 2012).

As amostras foram colhidas em um trecho de floresta aberta com bambu bastante alterada devido à extração madeireira e levadas para o Laboratório de Sementes Florestais e para a casa de vegetação do Parque Zoobotânico (PZ) da Universidade Federal do Acre (UFAC), localizado na cidade de Rio Branco, Acre (10'12'14.1"S 67\%2'18.3"W) onde foram realizados o estudo biométrico e o experimento de germinação. Para a avaliação biométrica foram selecionados ao acaso 30 racemos, os quais foram cortados rente aos galhos com a ajuda de um estilete. Um lote de 100 frutos maduros, sadios e sem deformações foi selecionado ao acaso de uma amostra de 237 frutos. Após a avaliação biométrica, os frutos foram despolpados manualmente e fez-se a avaliação biométrica das sementes.

A pesagem dos racemos, frutos e sementes foi feita em balança com precisão de $0,001 \mathrm{~g}$ e as medidas de comprimento, profundidade da polpa, diâmetro, largura e espessura com paquímetro digital de precisão de $0,01 \mathrm{~mm}$ ou régua graduada para os racemos. Os racemos foram avaliados quanto ao número de frutos, massa total do racemo, massa da raque (sem os frutos) e comprimento da raque. Os frutos foram avaliados quanto a sua massa, comprimento, diâmetro, profundidade de polpa e massa da polpa. A profundidade da polpa foi medida na porção mediana dos frutos e a massa da polpa foi obtida pela diferença entre a massa total do fruto e a da semente. As sementes foram avaliadas quanto a sua massa total, comprimento, largura e espessura. Para todas as variáveis avaliadas foram calculados os valores máximo e mínimo, média, desvio padrão (DP), coeficiente de variação $(C V)$ e 0 coeficiente de correlação de Pearson (r).

Para o experimento de germinação foram selecionadas 100 sementes visualmente sem defeitos e sem sinal de ataque por larvas. $O$ teor de água foi 
determinado em laboratório, de acordo com as Regras para Análise de Sementes (BRASIL, 2009) pela diferença de percentual de massa após secagem em estufa a $105 \stackrel{\circ}{\circ} \mathrm{C} \pm 3 \stackrel{\circ}{\circ} \mathrm{C}$ por 24 horas, com quatro repetições de cinco gramas. $\mathrm{O}$ teste de germinação, em delineamento inteiramente casualizado com quatro repetições de 25 sementes (LEONHARDT et al., 2011), utilizou areia peneirada como substrato, mantido úmido com irrigações diárias. As contagens das plântulas emergidas foram realizadas diariamente após a germinação da primeira semente, no vigésimo oitavo dia e por mais 49 dias, quando se constatou que as sementes restantes haviam apodrecido ou sido atacadas por larvas. Para avaliar o processo de germinação foi utilizado o critério fisiológico, em que foram consideradas como germinadas aquelas sementes onde houve protrusão da raiz (BRASIL, 2009).

A estatística descritiva, a distribuição de frequência dos valores e o coeficiente de correlação de Pearson foram calculados no programa estatístico BioEstat $5.0{ }^{\circledR}$. (AYRES et al., 2007). A percentagem, a velocidade e o tempo médio de germinação foram calculados no programa Microsoft Office Excel 2010, utilizando a metodologia indicada por LABOURIAU \& AGUDO (1987).

\section{RESULTADOS E DISCUSSÃO}

O número de frutos por racemo de Sorocea muriculata (Figura 1) variou de 2 a 7 , com $73,4 \%$ apresentando de 3 a 5 frutos (Figura $2 A$ ). A massa total do racemo

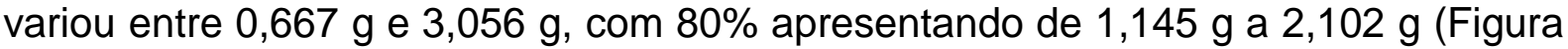
2B) e a massa da raque variou de $0,098 \mathrm{~g}$ a $0,344 \mathrm{~g}$ (Figura 2C), com $70 \%$ apresentando entre $0,147 \mathrm{~g}$ e $0,248 \mathrm{~g}$. O comprimento da raque variou entre $1,1 \mathrm{~cm}$ e 3,0 cm, com 70\% apresentando de $1,43 \mathrm{~cm}$ a 2,26 cm (Figura 2D). Os racemos com maior massa também apresentaram maior número de fruto e maior comprimento.
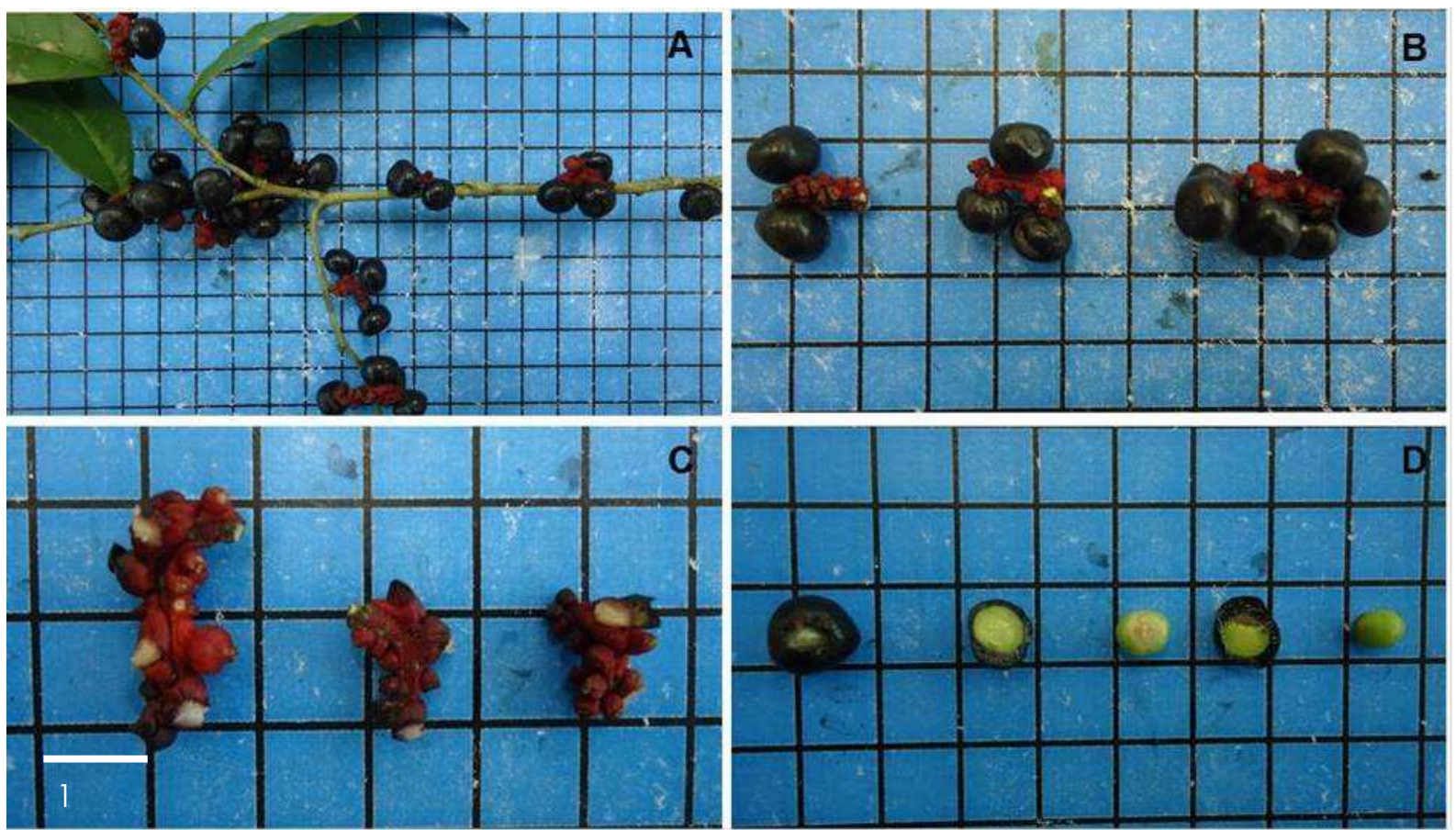

FIGURA 1 - Disposição dos racemos nos ramos (A), Racemos com frutos (B), Raque sem frutos (C) e Frutos e sementes (D) de Sorocea muriculata ocorrente na Floresta Estadual do Antimary, Bujari, Acre. 
Em média, a polpa do fruto de $S$. muriculata representou $66,23 \%(51,18 \%$ a $79,15 \%)$ da massa do fruto e a semente $33,37 \%$ (20,85\% a 48,82\%) (Tabela 1). O percentual de polpa dos frutos é uma característica que ajuda na tomada de decisão em relação ao aproveitamento de uma determinada espécie, seja de forma industrial ou como fruta fresca. A profundidade da polpa apresentou o maior coeficiente de variação $(35,37 \%)$, seguida pela massa da semente $(20,07 \%)$, pela massa da polpa $(18,86 \%)$ e pela massa total do fruto $(17,02 \%)$. A maior variabilidade nessas características pode ser resultante de fatores ambientais decorrentes da maior necessidade de água para a produção de frutos carnosos (TABARELLI et al., 2003).
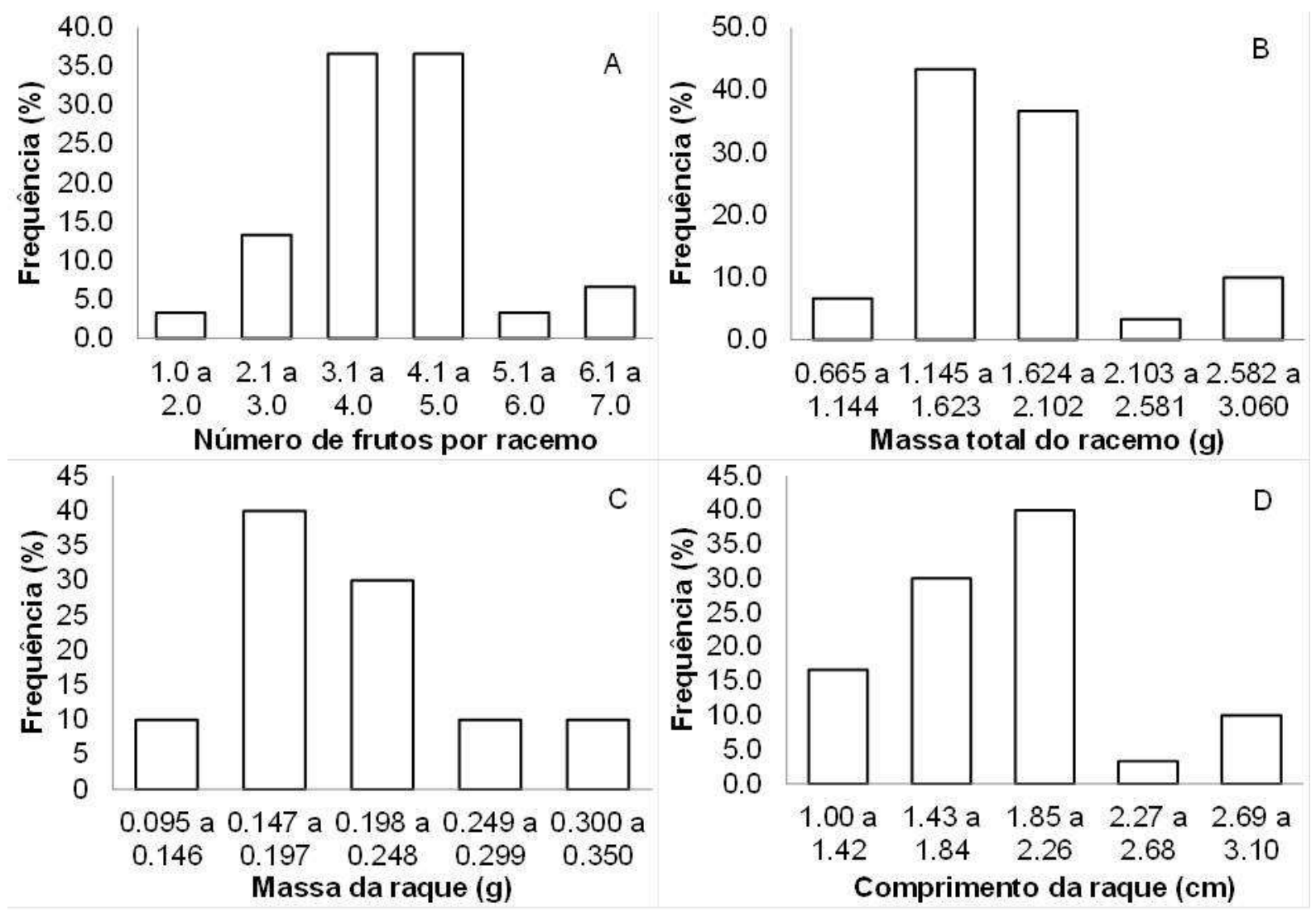

FIGURA 2 - Frequência (\%) do número de frutos por racemo (A), massa total do racemo (B), massa (C), e comprimento da raque (D) de Sorocea. muriculata oriunda da Floresta Estadual do Antimary, Bujari, Acre. 
TABELA 1 - Estatística descritiva da avaliação biométrica dos racemos, frutos e sementes de Sorocea muriculata oriundos da Floresta Estadual do Antimary, Bujari, Acre. DP=desvio padrão, $C V=$ coeficiente de variação.

\begin{tabular}{lccccc}
\hline Características biométricas & Mínimo & Máximo & Média & DP & CV (\%) \\
\hline Racemo & & & & & \\
\hline Número de frutos & 2,0 & 7,0 & 4,4 & 1,1 & 24,91 \\
Massa total (g) & 0,667 & 3,056 & 1,702 & 0,521 & 30,61 \\
Massa da raque (g) & 0,098 & 0,344 & 0,208 & 0,057 & 27,15 \\
Comprimento da raque (cm) & 1,1 & 3,0 & 1,9 & 0,49 & 26,47 \\
\hline Fruto & & & & & \\
\hline Massa total (g) & 0,155 & 0,404 & 0,292 & 0,050 & 17,02 \\
Comprimento (mm) & 4,97 & 8,60 & 5,88 & 0,47 & 8,04 \\
Diâmetro (mm) & 6,32 & 9,35 & 7,55 & 0,57 & 7,54 \\
Profundidade da polpa (mm) & 0,48 & 2,79 & 1,37 & 0,48 & 35,37 \\
Massa da polpa (g) & 0,087 & 0,283 & 0,195 & 0,037 & 18,86 \\
\% Polpa & 51,18 & 79,15 & 66,23 & 4,39 & 6,59 \\
\hline Semente & & & & & \\
\hline Massa (g) & 0,054 & 0,153 & 0,097 & 0,019 & 20,07 \\
\% Semente & 20,85 & 48,82 & 33,37 & 4,39 & 13,15 \\
Comprimento (mm) & 3,50 & 4,94 & 4,17 & 0,33 & 7,97 \\
Largura (mm) & 4,06 & 6,38 & 5,41 & 0,45 & 8,23 \\
Espessura (mm) & 3,96 & 5,60 & 4,81 & 0,35 & 7,26 \\
\hline
\end{tabular}

A massa total dos frutos de Sorocea muriculata variou entre $0,155 \mathrm{~g}$ e 0,404 $\mathrm{g}$, mas a maioria apresentou massa total entre $0,26 \mathrm{~g} \mathrm{e} 0,36 \mathrm{~g}$ (62\%) (Figura 3A). $\mathrm{O}$ comprimento variou entre $4,97 \mathrm{~mm}$ e $8,60 \mathrm{~mm}$ e o diâmetro entre $6,32 \mathrm{~mm}$ e 9,35 $\mathrm{mm}$. A maioria dos frutos apresentou comprimento entre $5,69 \mathrm{~mm} \mathrm{e} 6,46 \mathrm{~mm}(53 \%)$ e o diâmetro entre $6,93 \mathrm{~mm}$ e $8,16 \mathrm{~mm}$ (68\%) (Figuras 3B-C). A profundidade de polpa variou de $0,48 \mathrm{~mm}$ a $2,79 \mathrm{~mm}$ e a massa da polpa entre $0,087 \mathrm{~g} \mathrm{e} 0,283 \mathrm{~g}$. A maioria dos frutos apresentou profundidade de polpa entre $0,93 \mathrm{~mm}$ e $1,86 \mathrm{~mm}$ (58\%) e massa da polpa entre $0,14 \mathrm{~g}$ e $21 \mathrm{~g}(60 \%)$ (Figuras 3D-E). Os frutos de $S$. muriculata com maior massa também apresentaram maiores comprimento, diâmetro, profundidade de polpa e massa de polpa, assim como também tiveram as sementes com maior massa, comprimento, largura e espessura. 

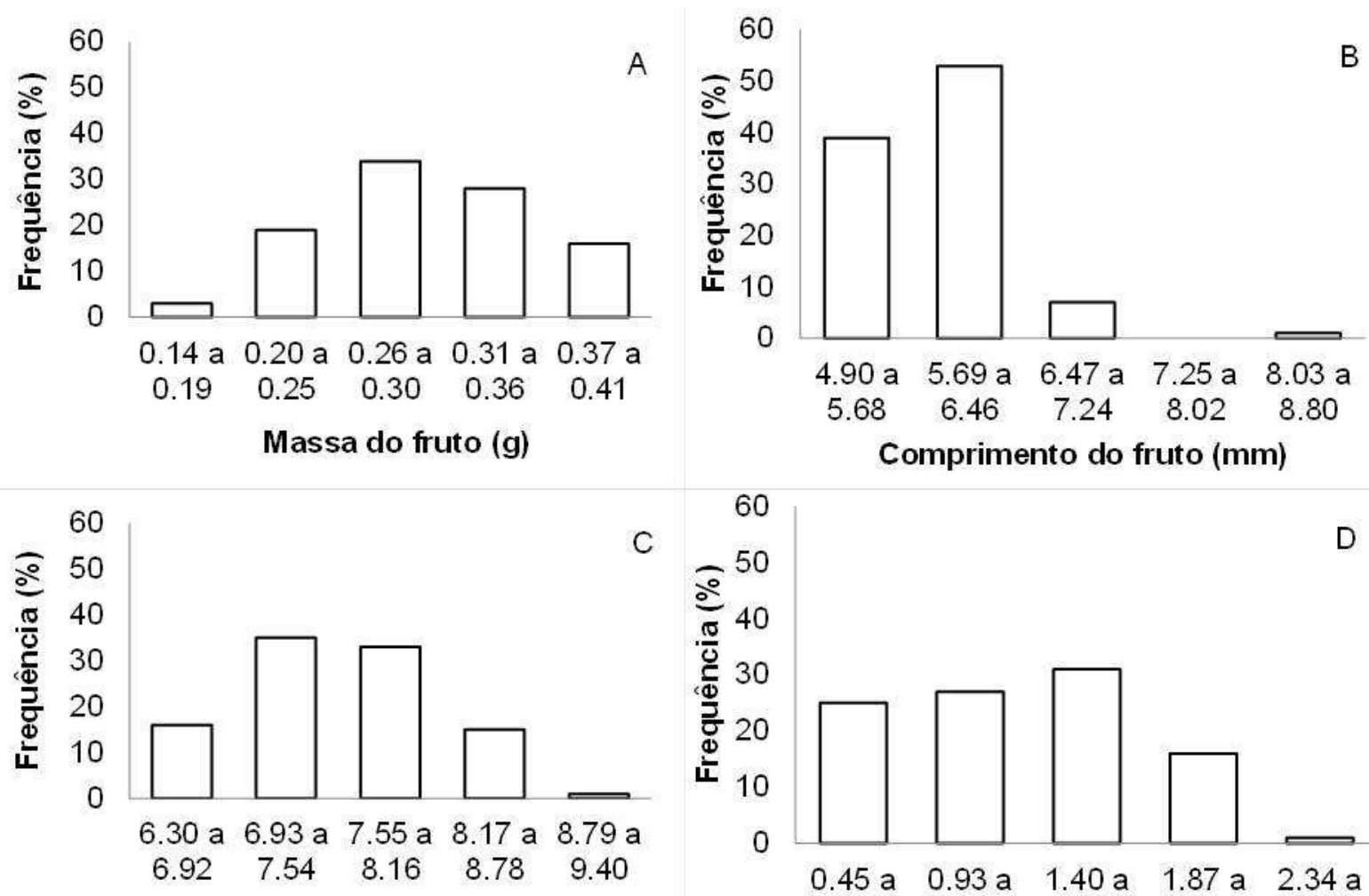

Diâmetro do fruto $(\mathrm{mm})$
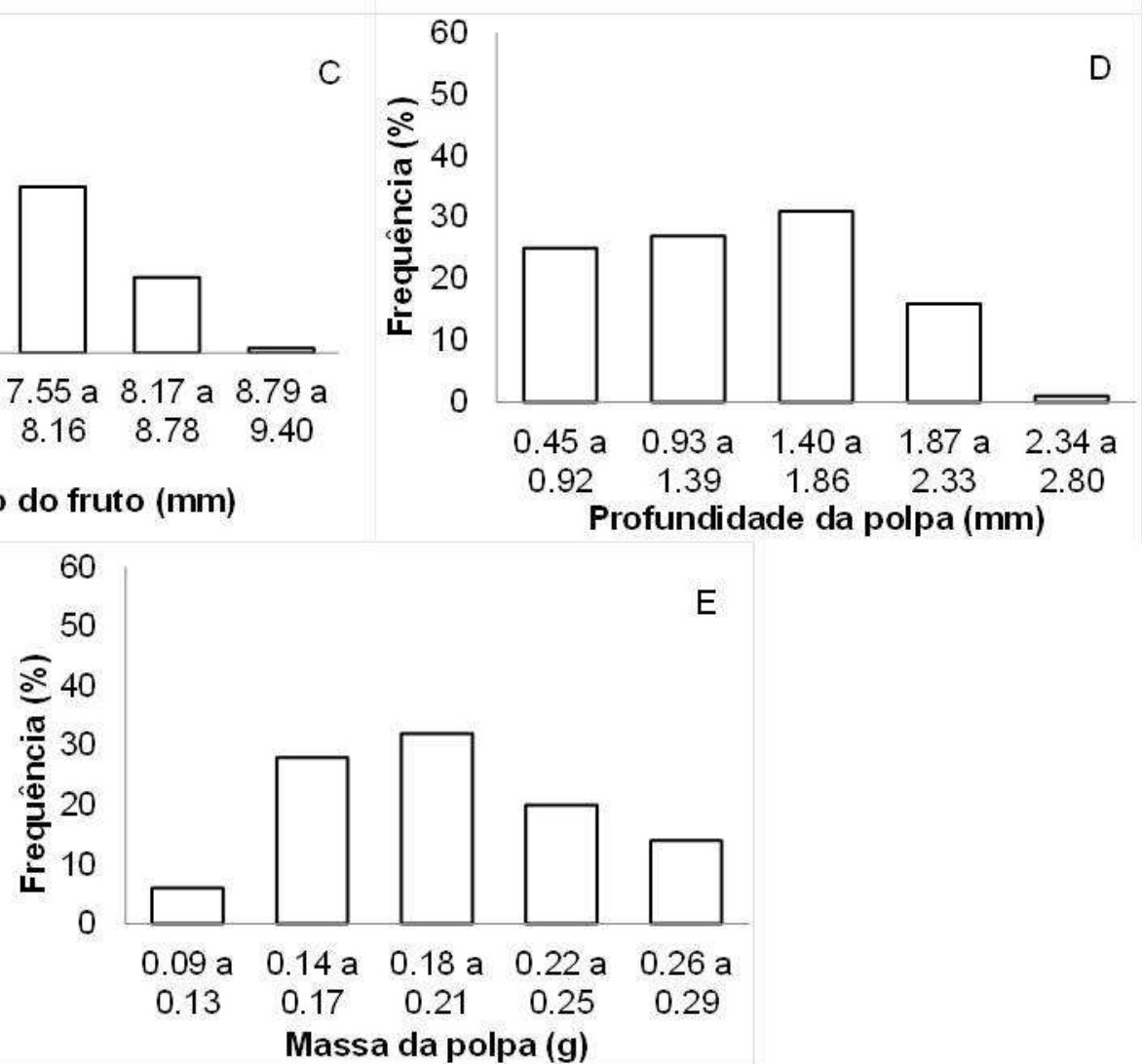

FIGURA 3 - Frequência (\%) de Massa (A), comprimento (B), diâmetro (C), profundidade da polpa (D) e massa da polpa (E) de frutos de Sorocea muriculata oriundos da Floresta Estadual do Antimary, Bujari, Acre.

A massa das sementes de $S$. muriculata variou de $0,054 \mathrm{~g}$ a $0,153 \mathrm{~g}$, com $84 \%$ apresentando massa entre $0,071 \mathrm{~g} \mathrm{e} 0,120 \mathrm{~g}$ (Figura $4 \mathrm{~A}$ ). $\mathrm{O}$ comprimento variou de $3,50 \mathrm{~mm}$ a $4,94 \mathrm{~mm}$, a largura entre $4,06 \mathrm{~mm}$ e $6,38 \mathrm{~mm}$ e a espessura entre $3,96 \mathrm{~mm}$ e $5,60 \mathrm{~mm}$ (Tabela 1). A maioria dos frutos apresentou comprimento entre $3,73 \mathrm{~mm}$ e $4,68 \mathrm{~mm}(85 \%)$, largura entre $4,53 \mathrm{~mm}$ e $5,93 \mathrm{~mm}(86 \%)$ e espessura entre $4,53 \mathrm{~mm}$ e $5,34 \mathrm{~mm}(65 \%)$ (Figuras 4B-D). As sementes com maior massa apresentaram também os maiores valores de comprimento, largura e espessura. 

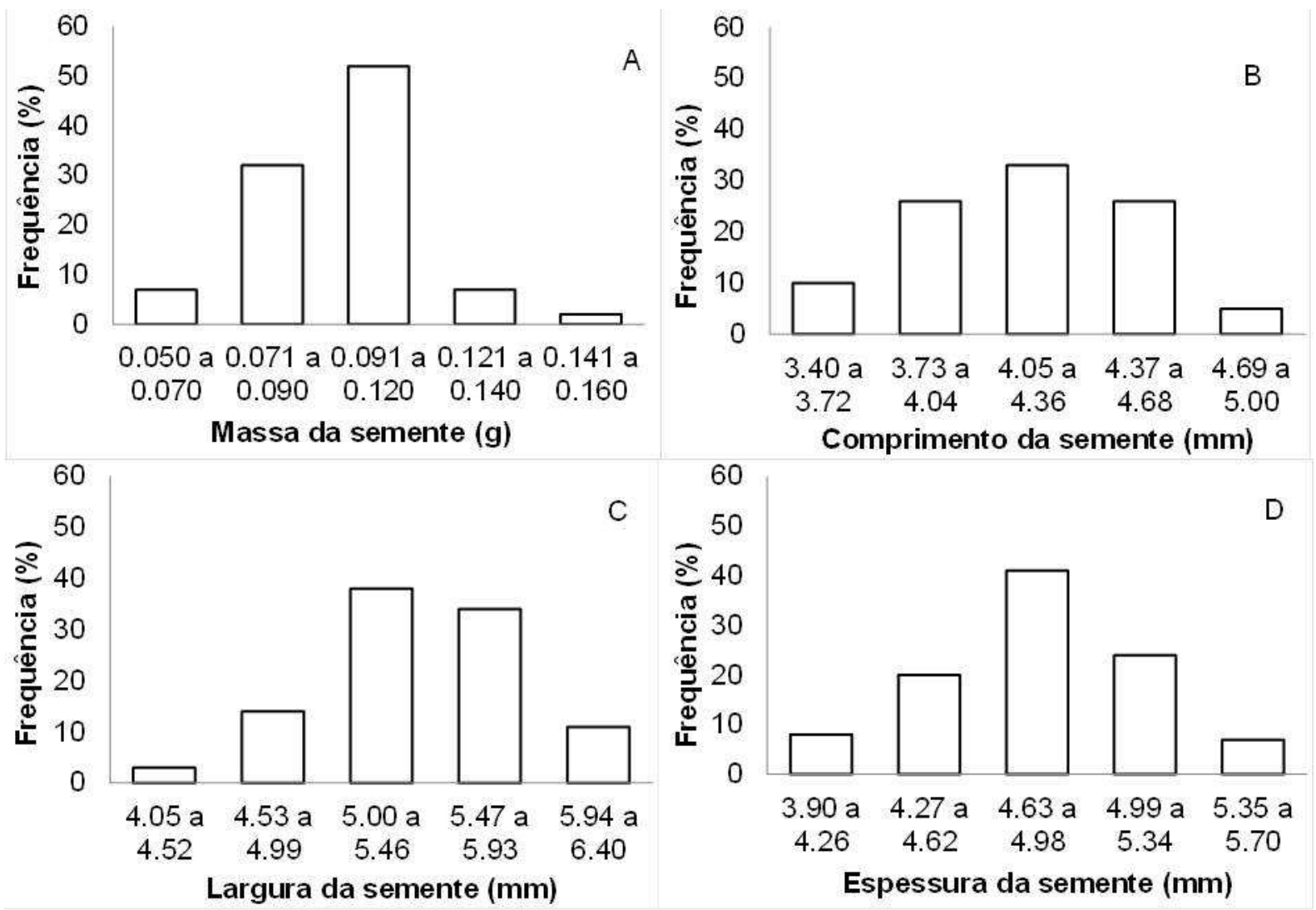

FIGURA 4 - Massa (A), comprimento (B), largura (C) e espessura (D) das sementes de Sorocea muriculata oriundas da Floresta Estadual do Antimary, Bujari, Acre.

Saber o tamanho da semente é importante, pois é uma característica que pode ou não influenciar na germinação da espécie. Por exemplo, em Euterpe espiritosantensis H.Q.B.Fern. (Arecaceae), sementes maiores (com maior massa, comprimento e diâmetro) apresentaram maior velocidade e percentual de germinação (MARTINS et al., 2000). O tamanho da semente também influenciou o percentual de germinação de Artocarpus heterophyllus Lam. (Moraceae), no entanto não influenciou sua velocidade de germinação (SILVA et al., 2010). SOCOLOWSKI et al. (2011) encontraram que para Tecoma stans (L.) Juss. ex Kunth (Bignoniaceae), a porcentagem de germinação foi maior para sementes com maior massa, assim como foi observado melhor desenvolvimento inicial das plântulas quando comparadas com aquelas originárias de sementes menores. Por outro lado, DRESCH et al. (2013) encontraram que em Campomanesia adamantium (Cambess.) O.Berg. (Myrtaceae) o tamanho do fruto dos quais as sementes eram provenientes influenciou positivamente o percentual de germinação, sendo que sementes de frutos menores tiveram maior percentual de germinação quando comparadas com as oriundas de frutos grandes.

Foi observada correlação forte e positiva entre as massas do fruto de $S$. muriculata e da polpa $(0,9418)$, ou seja, a massa do fruto é linearmente proporcional à massa da polpa, sendo que a polpa contribui, em média, com $66,23 \%$ da massa total do fruto. Também foi encontrada correlação forte e positiva entre a massa da semente e seu comprimento, largura e espessura $(0,8105 / 0,9185 / 0,8889)$ e entre a largura e espessura da semente $(0,8453)$ (Tabela 2$)$, indicando que essas variáveis 
são bastante relacionadas. VIEIRA \& GUSMÃO (2008) também encontraram alta correlação entre a massa do fruto e da polpa de Talisia esculenta (A. St.-Hil.) Radlk. (Sapindaceae) e destaca que essa relação é importante característica para essa espécie e determinante na valorização dos frutos no período de safra.

As correlações mais fracas e positivas foram observadas entre a massa do fruto e a profundidade da polpa $(0,0443)$, entre a profundidade da polpa e o diâmetro do fruto $(0,0851)$, indicando que a profundidade da polpa não está relacionada com a massa ou o diâmetro do fruto. Houve correlação fraca e negativa entre a profundidade de polpa e a massa da semente $(-0,0632)$ e entre a profundidade da polpa e o comprimento e largura da semente $(-0,0483 /-0.0021)$, indicando pouca relação entre essas variáveis (Tabela 2 ).

TABELA 2 - Correlação de Pearson ( $r$ ) para as variáveis biométricas dos frutos e sementes de Sorocea muriculata oriundos da Floresta Estadual do Antimary, Bujari, Acre.

\begin{tabular}{lc}
\hline Comparações & $\mathbf{r}$ \\
\hline Massa do fruto x Comprimento/Diâmetro do fruto & $0,5473 / 0,7980$ \\
Massa do fruto x Massa da polpa & 0.9418 \\
Massa do fruto x Massa da semente & 0,7732 \\
Massa do fruto x Profundidade da polpa & 0.0443 \\
Profundidade da polpa x Comprimento/Diâmetro do fruto & $-0,1090 / 0,0851$ \\
Profundidade da polpa x Comprimento/Largura/ & $-0,0483 /-0.0021 /$ \\
Espessura da semente & $-0,1013$ \\
Profundidade da polpa x Massa da semente & $-0,0632$ \\
Massa da semente x Comprimento/Espessura/ & $0,8105 / 0,9185 /$ \\
Largura da semente & 0,8889 \\
Comprimento da semente x Largura/Espessura da semente & $0,7376 / 0,7429$ \\
Largura da semente x Espessura da semente & 0,8453 \\
\hline
\end{tabular}

As sementes de Sorocea muriculata apresentavam em média $46,35 \%$ de umidade quando foram semeadas. A germinação iniciou-se a partir do vigésimo oitavo dia após a semeadura e estendeu-se até o septuagésimo segundo, ou seja, por mais 45 dias. O percentual de sementes germinadas de $S$. muriculata foi, em média, de $42 \%$, sua velocidade de germinação foi de 0,025 e o tempo médio de germinação foi de 40 dias. O gráfico de frequência relativa da emergência das sementes (Figura 5) apresentou caráter polimodal, indicando vários picos de germinação durante o período de observação. Para sementes de Sorocea bonplandii a germinação ocorre entre 30 e 40 dias, sua taxa de germinação varia de $50 \%$ a $58 \%$ e o teor de umidade entre 53\% e 57\% (CARVALHO, 2008; LEONHARDT et al., 2011), valores próximos aos obtidos nesse estudo.

Em relação a outras espécies da família Moraceae foi observado que o índice de velocidade de germinação foi baixo em Dorstenia cayapia Vell. Se comparado a outros autores situando-se entre $16 \%$ e $52 \%$, o quê pode depender da temperatura e do substrato utilizado (LUZ et al., 2010). Em Artocarpus heterophyllus verificou-se germinação entre $70 \%$ e $98 \%$ (SILVA et al., 2010), em Maclura tinctoria a germinação foi de $90 \%$ a $92 \%$ (BATTILANI et al., 2006), e em Brosimum gaudichaudii a variação foi entre $81 \%$ e $91 \%$ (FARIA et al., 2009). 


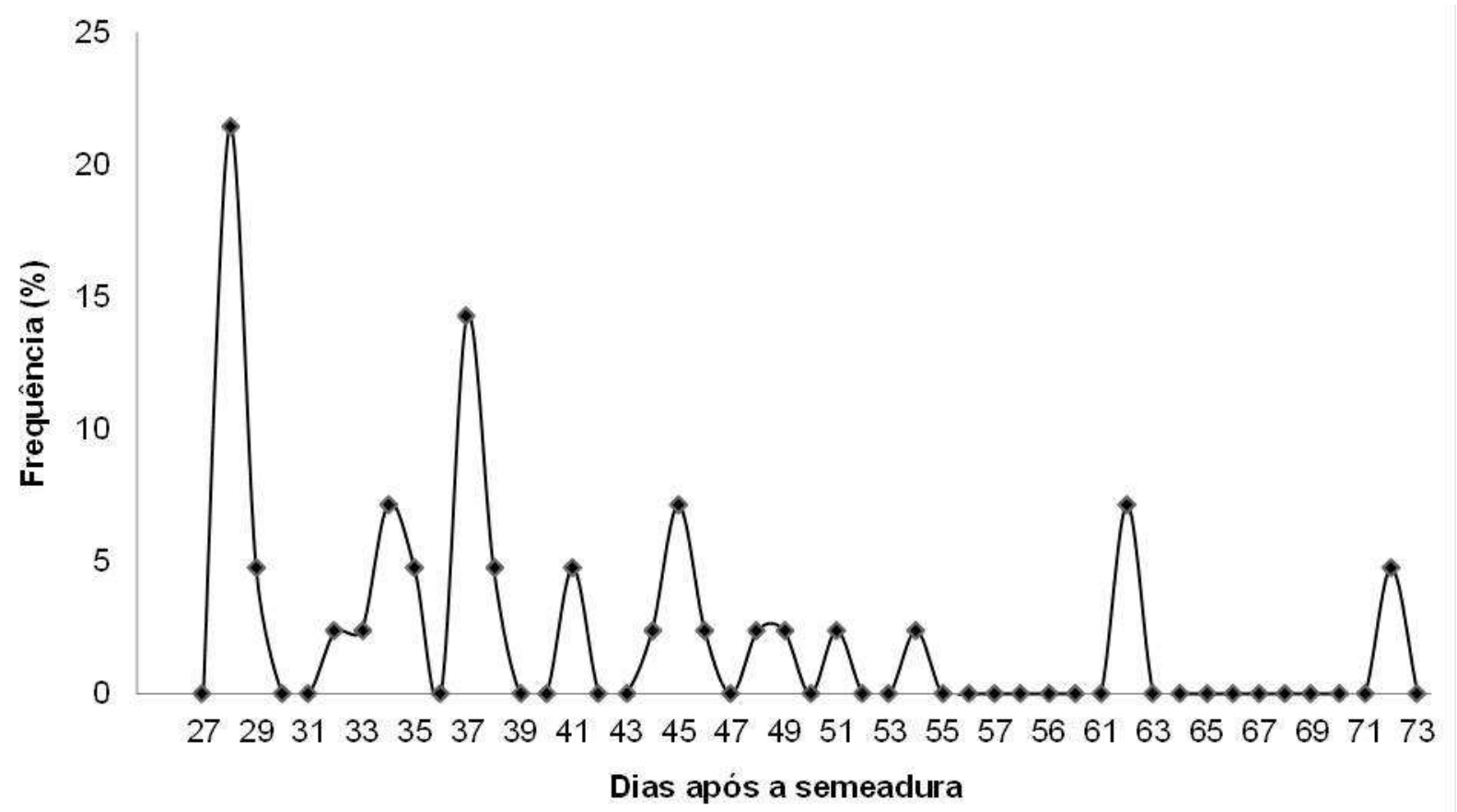

FIGURA 5 - Frequência relativa (\%) da emergência de sementes de Sorocea muriculata oriundas da Floresta Estadual do Antimary, Bujari, Acre, avaliadas na casa de vegetação do Parque Zoobotânico da UFAC, em Rio Branco, Acre.

\section{CONCLUSÕES}

Os racemos maiores de Sorocea muriculata apresentaram maior número de frutos e frutos com maior massa. Houve correlação positiva entre a massa do fruto e a massa da polpa e a da semente, indicando que frutos com maior massa total teve maior massa de polpa e maior massa de semente. As sementes apresentaram germinação baixa e irregular.

\section{REFERÊNCIAS}

ALVES, A. S.; LIMA, V. L. A.; FARIAS, M. S. S.; FIRMINO, M. C.; MEDEIROS, S. S. Desempenho germinativo de sementes de Leucena: avaliação de substratos e lâminas de água. Irriga, Botucatu-SP, edição especial, v.1, n.1, p.105-119, 2012.

AYRES, M.; AYRES JUNIOR, M.; AYRES, D. L.; SANTOS, A. A. S. Biostat 5.0: aplicações estatísticas nas áreas das ciências biológicas e médicas. Brasília: Sociedade Civil Mamirauá-Belém (MCT-CNPq), Belém. 2007. 364p. 1 CD-ROM.

BATTILANI, J. L.; SANTIAGO, E. F.; SOUZA, A. L. T. Morfologia de frutos, sementes e desenvolvimento de plântulas e plantas jovens de Maclura tinctoria (L.) D. Don. ex Steud. (Moraceae). Acta Botanica Brasilica, Belo Horizonte-MG, v.20, n.3, p.581589, 2006.

BATTILANI, J. L.; SANTIAGO, E. F.; DIAS, E. S. Morfologia de frutos, sementes, plântulas e plantas jovens de Guibourtia hymenifolia (Moric.) J. Leonard (Fabaceae). Revista Árvore, Viçosa-MG, v.35, n.5, p.1089-1098, 2011. 
BERG, C. C.; AKKERMANS, R. W. A. P. Studies on the flora of the Guianas 14: New taxa and combinations in Sorocea (Moraceae) and key to its species. Proceedings of the Koninklijke Nederlandse Akademie van Wetenschappen: Series C, v.88, n.4, p.381-394, 1985.

BRASIL. Regras para análise de sementes. Ministério da Agricultura, Pecuária e Abastecimento. Brasília: Mapa/ACS, 2009. 399p.

CARVALHO, P. E. R. Espécies arbóreas brasileiras. Brasília: Embrapa Informação Tecnológica, 2008. 593p.

CHRISTRO, L. F. et al. Biometric analysis of seeds of genotypes of physic nut (Jatropha curcas L.). Agropecuária Científica no Semiárido, Campina Grande-PB, v.8, n.1, p.01-03, 2012.

DORNELES, M. C.; RANAL, M. A.; SANTANA, D. G. Germinação de sementes e emergência de plântulas de Anadenanthera calubrina (Vell.) Brenan var. cebil (Griseb.) Altschut, Fabaceae, estabelecida em fragmentos florestais do cerrado, MG. Ciência Florestal, Santa Maria-RS, v.23, n.3, p.291-304, 2013.

DRESCH, D. M.; SCALON, S. P. Q.; MASETTO, T. E.; VIEIRA, M. C. Germinação e vigor de sementes de gabiroba em função do tamanho do fruto e semente. Pesquisa Agropecuária Tropical, Goiânia-GO, v.43, n.3, p.262-271, 2013.

FARIA, R. A. P. G.; SILVA, A. N.; ALBUQUERQUE, M. C. F.; COELHO, M. F. B. Características biométricas e emergência de plântulas de Brosimum gaudichaudii Tréc. oriundas de diferentes procedências do cerrado mato-grossense. Revista Brasileira de Plantas Medicinais, Paulínia-SP, v.11, n.4, p.414-421, 2009.

FELIPPI, M. MAFFRA, C. R. B.; CANTARELLI, E. B.; ARAÚJO, M. M.; LONGHI, S. J. Fenologia, morfologia e análise de sementes de Apuleia leiocarpa (Vogel) J.F.Macbr. Ciência Florestal, Santa Maria-RS, v.22, n.3, p.477-491, 2012a.

FELIPPI, M. MAFFRA, C. R. B.; CANTARELLI, E. B.; ARAÚJO, M. M.; LONGHI, S. J. Fenologia, morfologia e análise de sementes de Cordia trichotoma (Vell.) Arráb. ex Steud. Ciência Florestal, Santa Maria-RS, v.22, n.3, p.631-641, $2012 b$.

FERREIRA, C. D.; SOUTO, P. C.; LÚCIO, A. M. F. N.; SOUTO, J. S.; SOUZA, B. V. Avaliações biométricas e germinação de sementes de Coaçu (Triplaris surinamensis Cham.). Revista Brasileira de Tecnologia Aplicada nas Ciências Agrárias, Guarapuava-PR, v.5, n.1, p.147-162, 2012.

GONÇALVES, L. G. V.; ANDRADE, F. R.; MARIMON JUNIOR, B. H.; SCHOSSLER, T. R.; LENZA, E.; MARIMON, B. S. Biometria de frutos e sementes de mangaba (Hancornia speciosa Gomes) em vegetação natural na região leste de Mato Grosso, Brasil. Rev. de Ciências Agrárias, Lisboa, v.36, n.1, p.36-40, 2013. 
GUSMÃO, E.; VIEIRA, F. A.; FONSECA, E. M. Biometria de frutos e endocarpos de murici (Byrsonima verbascifolia Rich. Ex A. Juss.). Cerne, Lavras, v.12, n.1, p.84-91, 2006.

HERBÁRIO INPA. Sorocea muriculata. 2015. Rede speciesLink. Disponível em: <http://www.splink.org.br>. Acesso em: 10 ago. 2015.

HERZOG, N. F. M.; MALAVASI, M. M.; MALAVASI, U. C. Morfometria dos frutos e germinação de sementes de Campomanesia xanthocarpa O. Berg. Semina: Ciências Agrárias, Londrina-PR, v.33, n.4, p.1359-1366, 2012.

KRATZ, D.; BASSACO, M. V. M. NOGUEIRA, A. C. Influence of water stress on germination of Zeyheria montana. Journal of Biotechnology and Biodiversity, Gurupi-TO, v.4, n.2, p.140-145, 2013.

LABOURIAU, L. G.; AGUDO, M. On the physiology of seed germination in Salvia hispanica L. I. Temperature effects. Anais da Academia Brasileira de Ciências, Rio de Janeiro, v.59, n.1, p. 37-56, 1987.

LEONHARDT, C.; CALIL, A. C.; PEREIRA, C. M.; FIOR, C. S. Comportamento germinativo de sementes de Sorocea bonplandii (Baill.) W.C. Burger, Lanjouw \& Boer - Moraceae. Iheringia, Série Botânica, Porto Alegre, v.66, n.1, p.133-138, 2011.

LUZ, J. M. Q.; CARVALHO, A. F.; SANTANA, D. G. ; SILVA, M. A. D. Germinação de sementes e emergência de plântulas de carapiá: espécie primitiva e medicinal. Horticultura Brasileira, Vitória da Conquista-BA, v.28, n.1, p.107-110, 2010.

MARTINS, C. C.; NAKAGAWA, J.; BOVI, M. L. A. Influência do peso das sementes de palmito-vermelho (Euterpe espiritosantensis Fernandes) na porcentagem e na velocidade de germinação. Revista Brasileira de Sementes, Londrina-PR, v.22, n.1, p.47-53, 2000.

PEREIRA, P. A. Investigação química de Sorocea bonplandii (Baillon) Burger, Lanjouw e Boer (Moraceae). 2005. 114f. Dissertação (Mestrado em Farmácia) Universidade Federal de Santa Catarina, Florianópolis-SC, 2005.

ROSS, S. A.; RODRÍGUEZ-GUZMÁN, R.; RADWAN, M. M.; JACOB, M.; DING, Y.; LI, X.-C.; FERREIRA, D.; MANLY, S. P. Sorocenols $G$ and H, anti-MRSA oxygen heterocyclic Diels-Alder-type adducts from Sorocea muriculata roots. Journal of Natural Products, Washington, USA, v.71, n.10, p.1764-1765, 2008.

SILVA, S. M. P. Políticas Públicas e Ambientalismo no Agroamazônico: um estudo de caso do Acre (1999-2010). 2012. 343f. Tese (Doutorado em Ciências Sociais) - Universidade Federal Rural do Rio de Janeiro, Rio de Janeiro - RJ, 2012.

SILVA, K. S.; MENDONÇA, V.; MEDEIROS, L. F. ; FREITAS, P. S. C.; GÓIS, G. B. Influência do tamanho da semente na germinação e vigor de mudas de jaqueira 
(Artocarpus heterophyllus Lam.). Revista Verde de Agroecologia e Desenvolvimento Sustentável, Pombal-PB, v.5, n.4, p.217-221, 2010.

SOCOLOWSKI, F.; VIEIRA, D. C. M.; TAKAKI, M. Seed mass of Tecoma stans L. Juss. ex Kunth (Bignoniaceae): effects on emergence and seedling development under full sun and shade. Biota Neotropica, Campinas-SP, n.11, v.2, p.171-178, 2011.

SOUZA, V. C.; LORENZI, H. Botânica sistemática: guia ilustrado para identificação das famílias de Angiospermas da flora brasileira baseado em APG II. 3 ed. Nova Odessa: Instituto Plantarum, 2012. 768p.

TABARELLI, M.; VICENTE, A.; BARBOSA, D. C. A. Variation of seed dispersal spectrum of woody plants across a rainfall gradient in northeastern Brazil. Journal of Arid Environments, Oxford, England, v.53, p.197-210, 2003.

VIEIRA, F. de A.; GUSMÃO, E. Biometria, armazenamento de sementes e emergência de plântulas de Talisia esculenta Radlk. (Sapindaceae). Ciência e Agrotecnologia, Lavras, v. 32, n. 4, p. 1073-1079, 2008. 